\title{
Illumination Level Effects on Macroscopic Parameters of a Bifacial Solar Cell
}

\author{
Nzonzolo', D. Lilonga-Boyenga1, G. Sissoko² \\ ${ }^{1}$ Ecole Nationale Supérieure Polytechnique (ENSP), Université Marien Ngouabi, Brazzaville, Congo \\ ${ }^{2}$ Faculté des Sciences et Technologies (FST), Université Cheikh Anta Diop, Dakar, Sénégal \\ Email: nzonzolo@gmail.com, lilongadesire@yahoo.fr
}

Received 26 December 2013; revised 26 January 2014; accepted 5 February 2014

Copyright (C) 2014 by authors and Scientific Research Publishing Inc.

This work is licensed under the Creative Commons Attribution International License (CC BY). http://creativecommons.org/licenses/by/4.0/

(c) (i) Open Access

\begin{abstract}
This study presents a method based on the experimental measurement of the short-circuit current $\left(I_{c c}\right)$ and the open circuit voltage $\left(V_{c o}\right)$ of the solar cell. It permits the determination of recombination parameters such as: diffusion length $(L)$, back surface recombination velocity $(S b)$, intrinsic junction recombination velocity (Sjo), and macroscopic parameters in particular, the shunt and series resistances of a bifacial solar cell for various illumination levels $(n)$. Illumination level effects on macroscopic parameters are highlighted.
\end{abstract}

\section{Keywords}

Solar Cell; Photo Voltage; Recombination Velocity; Diffusion Length; Series Resistance; Shunt Resistance

\section{Introduction}

The study of solar cells uses several parameters among which the illumination level $(n)$ whose effects are considerable in the production of solar energy.

Many studies dedicated to the illumination level have shown that all wavelengths of a multispectral light are not absorbed by the solar cell, and a modeling of the illumination level had been made, taking account only wavelengths absorptive by the photovoltaic cell [1] [2]. It was shown that the illumination level has a direct effect on the carriers density and thus on the current density and the photo voltage [3] [4].

For the determination of the microscopic parameters particularly the diffusion length (L), several methods were proposed; which one can find the insertion of short-circuit current technique method and the report of short-circuit currents technique method [3], whose determination of the parameters is made for only one level of illumination. I. Ly et al. have determined recombination parameters for various illumination levels, from which 
they evaluated only microscopic parameters of a bifacial solar cell [4]. However, they have not determined macroscopic parameters in particular, shunt and series resistance [5]-[8].

In this paper, the illumination effects on macroscopic parameters of a solar cell, subjected to various illumination levels, are investigated.

From the experimental measurement of the short-circuit current and photo voltage for various illumination levels, the diffusion length, the back surface recombination velocity $(\mathrm{Sb})$ and the intrinsic junction recombination velocity (Sjo) are determined. Subsequently, shunt and series resistances are deduced.

\section{Theoretical Analysis}

Let us consider photovoltaic cell illuminated successively on the front surface and on the back surface such as shown on the Figure 1.

Since $\alpha$, being the face considered. For the calculation of the current density, the solar cell emitter contribution to the global photocurrent density is assumed to be negligible comparatively to base one, and the problem is assumed one-dimensional, i.e. depending only on the depth of base $\mathrm{x}$.

\subsection{Minority Carrier's Density}

According to continuity equation, the minority carrier's density in the base $\delta_{\alpha}(x)$ obeys to the following equation [3].

$$
\frac{\partial^{2} \delta_{\alpha}(x)}{\partial x^{2}}-\frac{\delta_{\alpha}(x)}{L^{2}}=-\frac{g_{\alpha}(x)}{D}
$$

where $g_{\alpha}(x)$ is the carriers generation rate. $\alpha=1$ and $\alpha=2$ corresponding to the solar cell illuminated on its front surface and back surface respectively. $L$ is the diffusion length and $D$, the diffusion constant.

This carrier's density is subjugated to the following boundary conditions:

$$
\left.D \frac{\partial \delta_{\alpha}(x)}{\partial x}\right|_{x=0}=S j_{\alpha} \delta_{\alpha}(0)
$$

at the junction and

$$
\left.D \frac{\partial \delta_{\alpha}(x)}{\partial x}\right|_{x=H}=-S b_{\alpha} \delta_{\alpha}(H)
$$

at the back surface.

$S j$ and $S b$ are respectively the junction recombination velocity and the back surface recombination velocity.

Like Gaye et al. [1], we will retain only three most absorptive wavelengths, in the expressions of carrier generation rate.

Thus,

$$
g_{1}(x)=\sum_{1}^{3} n a_{i} \exp \left(-b_{i} x\right) \text { and } g_{2}(x)=\sum_{1}^{3} n a_{i} \exp \left[-b_{i}(H-x)\right]
$$

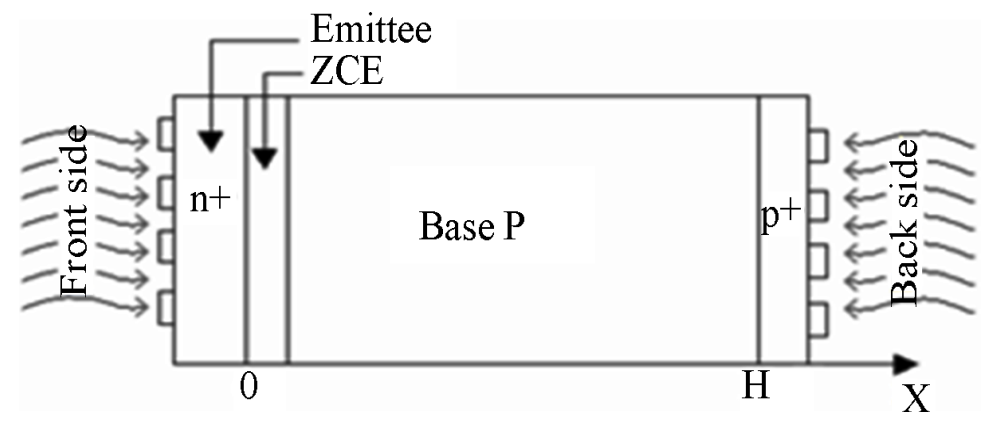

Figure 1. Bifacial solar cell. 
$a_{i}$ and $b_{i}$ are the constants deduced from modeling of the generation rate considered for the overall solar radiation spectrum [2]. $n$ is the sun number which characterizes the illumination level. The resolution of Equation (1) associated to the boundary conditions (2) and (3) yield to the expressions of carrier's density (4) and (5).

$$
\begin{gathered}
\delta_{1}(x)=A_{1} \operatorname{ch}\left(\frac{x}{L}\right)+B_{1} \operatorname{sh}\left(\frac{x}{L}\right)-\sum_{1}^{3} K_{i} \exp \left(-b_{i} x\right) \\
\delta_{2}(x)=A_{2} \operatorname{ch}\left(\frac{x}{L}\right)+B_{2} \operatorname{sh}\left(\frac{x}{L}\right)-\sum_{1}^{3} K_{i} \exp \left[-b_{i}(H-x)\right]
\end{gathered}
$$

where:

$$
K_{i}=\frac{n L^{2}}{D\left(b_{i}^{2} L^{2}-1\right)} a_{i}
$$

$A_{1}, B_{1}, A_{2}$, and $B_{2}$ are given by :

$$
\begin{gathered}
A_{1}=\sum_{1}^{3} K_{i} \frac{\left(\frac{S b-b_{i} D}{Y}\right) \exp \left(-b_{i} H\right)+b_{i} L-\frac{X}{Y}}{\frac{X}{Y}+\frac{S j L}{D}} \\
B_{1}=\frac{S j L}{D} \sum_{1}^{3} K_{i} \frac{\left(\frac{S b-b_{i} D}{Y}\right) \exp \left(-b_{i} H\right)-\frac{X}{Y}\left(\frac{b_{i} D}{S j}+1\right)}{\frac{X}{Y}+\frac{S j L}{D}} \\
A_{2}=\sum_{1}^{3} K_{i} \frac{\frac{S b+b_{i} D}{Y}+\left(\frac{S j L}{D}-b_{i} L\right) \exp \left(-b_{i} H\right)}{\frac{X}{Y}+\frac{S j L}{D}} \\
B_{2}=\frac{S j L}{D} \sum_{1}^{3} K_{i} \frac{\frac{S b+b_{i} D}{Y}+\left(\frac{S j L}{D}-1\right) \exp \left(-b_{i} H\right)}{\frac{X}{Y}+\frac{S j L}{D}} \\
X=\frac{D}{L} \operatorname{sh}\left(\frac{H}{L}\right)+S b c h\left(\frac{H}{L}\right) \text { and } \\
Y=\frac{D}{L} c h\left(\frac{H}{L}\right)+S b \cdot \operatorname{sh}\left(\frac{H}{L}\right)
\end{gathered}
$$

\subsection{Photocurrent Density}

The photocurrent density $(J)$ and the minority carriers density are related by the following equation [2]:

$$
J_{\alpha}=\left.q D \frac{\partial \delta_{\alpha}(x)}{\partial x}\right|_{x=0}
$$

For an illumination on the front surface, one obtains:

$$
J_{1}=q \cdot S j \sum_{1}^{3} K_{i} \frac{\frac{\left(S b-b_{i} D\right) \exp \left(-b_{i} H\right)}{Y}+b_{i} L-\frac{X}{Y}}{\frac{X}{Y}+\frac{S j L}{D}}
$$

and for an illumination on the back surface: 


$$
J_{2}=q \cdot S j \sum_{1}^{3} K_{i} \frac{\frac{S b+b_{i} D}{Y}-\left(\frac{X}{Y}+b_{i} L\right) \exp \left(-b_{1} H\right)}{\frac{X}{Y}+\frac{S j L}{D}}
$$

This photocurrent density being constant for very large values of junction recombination velocity, we can thus write that:

$$
\left.\frac{\partial J}{\partial S j}\right|_{S j \rightarrow \infty}=0
$$

This last equation enables us to obtain back surface recombination velocities according to the diffusion length, namely: for an illumination on the front surface,

$$
S b_{1}=D \sum_{1}^{3} \frac{b_{i}\left[\operatorname{ch}\left(\frac{H}{L}\right)-\exp \left(-b_{i} H\right)\right]-\frac{1}{L} \operatorname{sh}\left(\frac{H}{L}\right)}{\operatorname{ch}\left(\frac{H}{L}\right)-L \cdot \operatorname{sh}\left(\frac{H}{L}\right) \cdot b_{i}-\exp \left(-b_{i} H\right)}
$$

and for an illumination on the back surface,

$$
S b_{2}=D \sum_{1}^{3} \frac{\left[b_{i} \cdot \operatorname{ch}\left(\frac{H}{L}\right)+\frac{1}{L} \operatorname{sh}\left(\frac{H}{L}\right)\right] \exp \left(-b_{i} H\right)-b_{i}}{1-\left[b_{i} L \cdot \operatorname{ch}\left(\frac{H}{L}\right)+\operatorname{sh}\left(\frac{H}{L}\right)\right] \exp \left(-b_{i} H\right)}
$$

\subsection{Short-Circuit Current Density}

The short-circuit current density can be explicitly deduced according to the diffusion length, from the photocurrent density, if: the junction recombination velocity value exceeds a value about $S j=10^{6} \mathrm{~cm} / \mathrm{s}$; the back surface recombination velocity is replaced by its expression (15) for the front surface illumination and (16) for the back surface illumination.

\subsection{Photo Voltage}

Since $\delta_{\alpha}(x)$ is determined, the photo voltage can be obtained by the Boltzmann relation [3]:

$$
V=V_{T} \log \left(\frac{N b}{n_{i}^{2}} \delta_{\alpha}(0)+1\right)
$$

$N b$ represents the base doping density; $n_{i}$ the intrinsic carriers' concentration and $V_{T}$ the thermal voltage.

\subsection{Shunt and Series Resistances}

From electric view point, a solar cell feeding a load resistance $R_{\mathrm{L}}$, can be replaced by its electrical equivalent circuit given in Figure 2 [2].

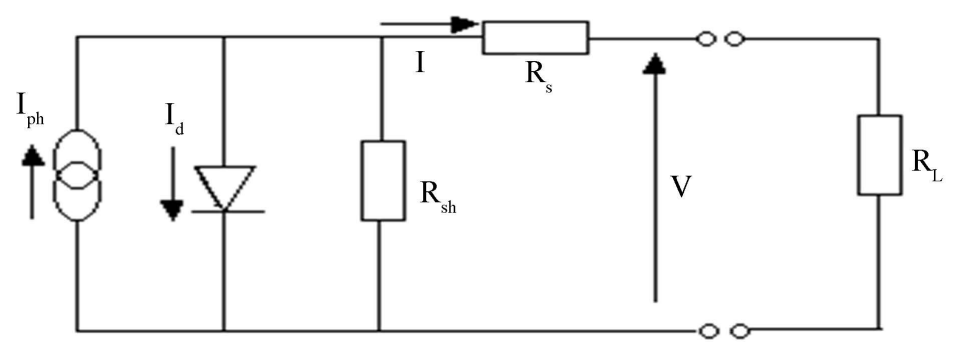

Figure 2. Electrical equivalent circuit of a solar cell under illumination. 
$R_{\mathrm{s}}$ represents the series resistance, $R_{s h}$ the shunt resistance, $I_{p h}$ the photocurrent and $I_{d}$ the diode current. One find from this electrical equivalent circuit the load resistance $R_{L}$ :

$$
R_{L}=\frac{V}{I}=\frac{V\left(R_{s}+R_{s h}\right)}{R_{s h}\left(I_{p h}-I_{d}\right)-V}
$$

where $I_{d}$ is the classic diode current

$$
I_{d}=q \cdot \operatorname{Sjo} \cdot \frac{n_{i}^{2}}{N b}\left[\exp \left(\frac{V_{d}}{V_{T}}\right)-1\right]
$$

The Equation (18) shows that the load resistance is function of junction recombination velocity $S j$ and the shunt resistance $R_{\text {sh }}$ can be evaluated by considering the open circuit operation of the solar cell [9].

Series resistance is corresponding to the very high value of the junction recombination velocity, i.e. to shortcircuit operation of the solar cell [9]. These two operations process enabled us to obtain the profiles of shunt resistance and series resistance according to the intrinsic junction recombination velocity Sjo:

$$
R_{s h}=\frac{V}{I_{p h}-I_{d}}
$$

and

$$
R_{s}=\frac{V_{d}-V}{I}
$$

\section{Results and Discussion}

Using the Matlab software, we have calculated the photocurrent density and the photo voltage of the solar cell from which we have deduced current-voltage characteristic.

\subsection{Photocurrent Density}

The profile of the photocurrent density versus to the junction recombination velocity $S j$, for various illumination levels is illustrated in Figure 3.

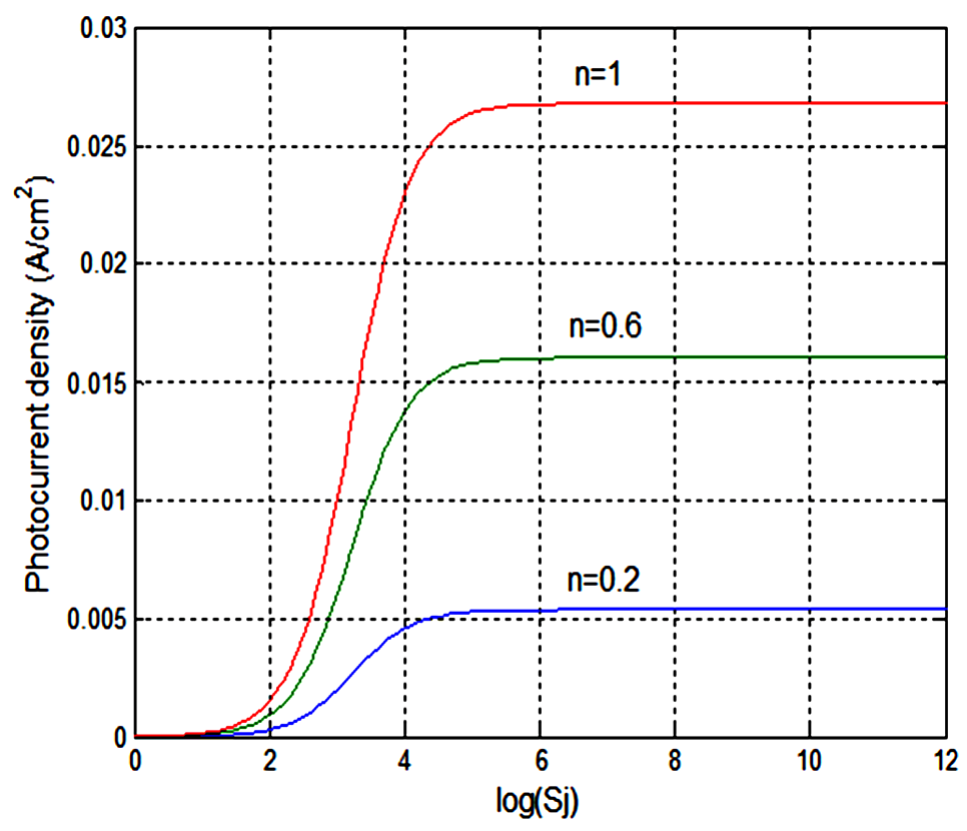

Figure 3. Photocurrent density versus junction recombination velocity $S j$ for various illumination levels. $D=26 \mathrm{~cm}^{2} / \mathrm{s}, L=0.01 \mathrm{~cm}, S b=1000 \mathrm{~cm} / \mathrm{s}$. 
In one hand we can note that this photocurrent density remains null until $100 \mathrm{~cm} / \mathrm{s}$ then increases quickly to reach a value of saturation from $10^{6} \mathrm{~cm} / \mathrm{s}$ which corresponds to the short-circuit photocurrent density.

In the other hand, we can also see that short-circuit photocurrent density increases when the illumination level increases. This profile is in conformity with the theoretical predictions [5] [10].

\subsection{Photo Voltage}

In Figure 4, we represented the photo voltage versus to the junction recombination velocity for various illumination levels.

We note that for junction recombination velocities lower than $300 \mathrm{~cm} / \mathrm{s}$, the photo voltage is constant and correspond to the open circuit photo voltage. Beyond this value, the photo voltage decreases linearly, and cancels when the recombination velocity corresponds to the short circuit junction recombination velocity.

It can be also noted that the short-circuit junction recombination velocity increases when the illumination increases.

\subsection{Current-Voltage Characteristics}

The current-voltage characteristic of the solar cell is represented in Figure 5.

One note that for photo voltage lower than $0.65 \mathrm{~V}$, the current density is constant. From this value, the current density decreases drastically to reach a zero value for a photo voltage equal to $0.75 \mathrm{~V}$, owing to the decrease of junction recombination velocity, from short-circuit to the open circuit.

\subsection{Short-Circuit Photocurrent Density}

The profile of the short-circuit photocurrent density versus to the diffusion length, for various illumination levels is illustrated in Figure 6.

As expected, this short circuit current increases according to the diffusion length and the illumination level.

These curves permit us to determine the diffusion length value $L$, when the short-circuit current density $J_{c c}$, and the illumination level $\mathrm{n}$ are known.

\subsection{Macroscopic Parameters Determination}

The profiles of these curves plotted above for various illumination levels, are in accordance with the results obtained by I. Ly et al. [4] and A. Hamadou et al. [5].

The same, we have determined macroscopic parameters of a bifacial solar cell, from the experimental values of the short-circuit photocurrent, the open circuit photo voltage and the illumination levels.

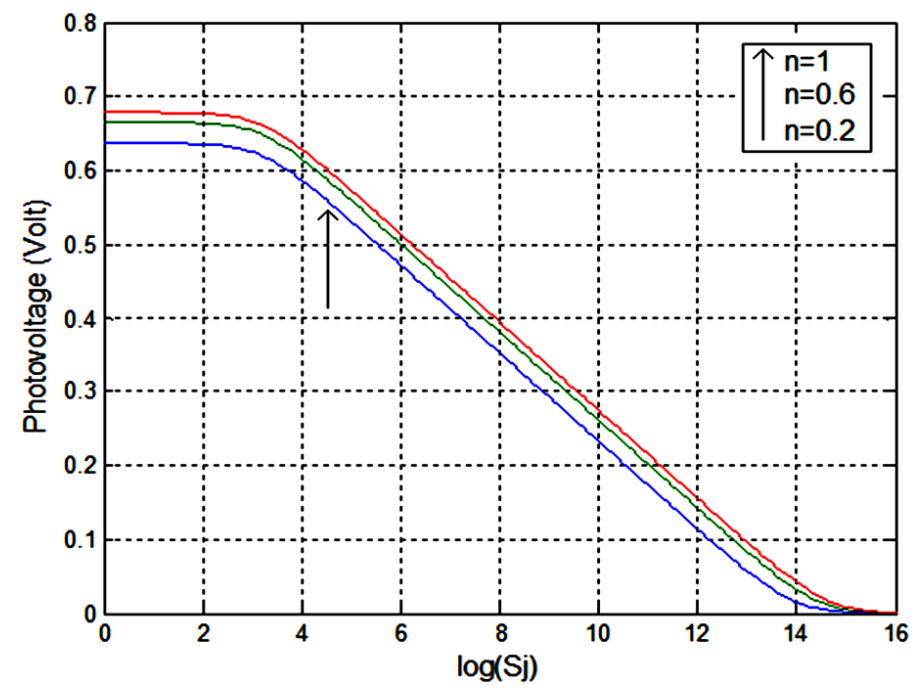

Figure 4. Photovoltage according to $S j$ for various Illumination levels $n$. $D=26 \mathrm{~cm}^{2} / \mathrm{s} ; S b=1000 \mathrm{~cm} / \mathrm{s}$, front side illumination. 


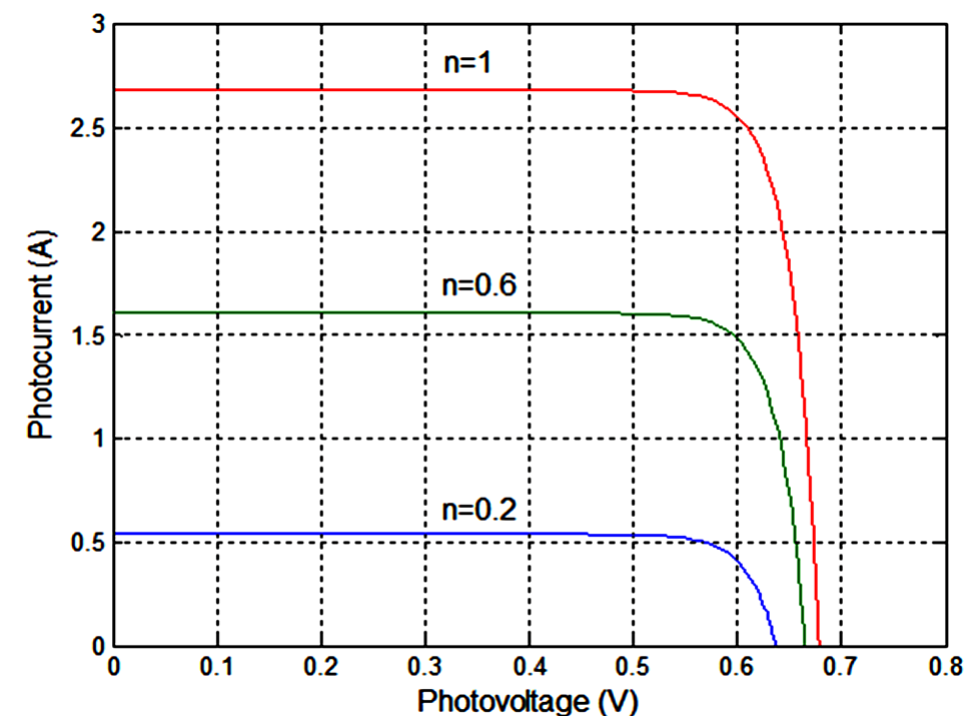

Figure 5. Current-voltage characteristic for various values of $n$. front surface illumination. $D=26 \mathrm{~cm}^{2} / \mathrm{s}, S b=1000 \mathrm{~cm} / \mathrm{s}, L=0.01 \mathrm{~cm}, H=0.03 \mathrm{~cm}$.

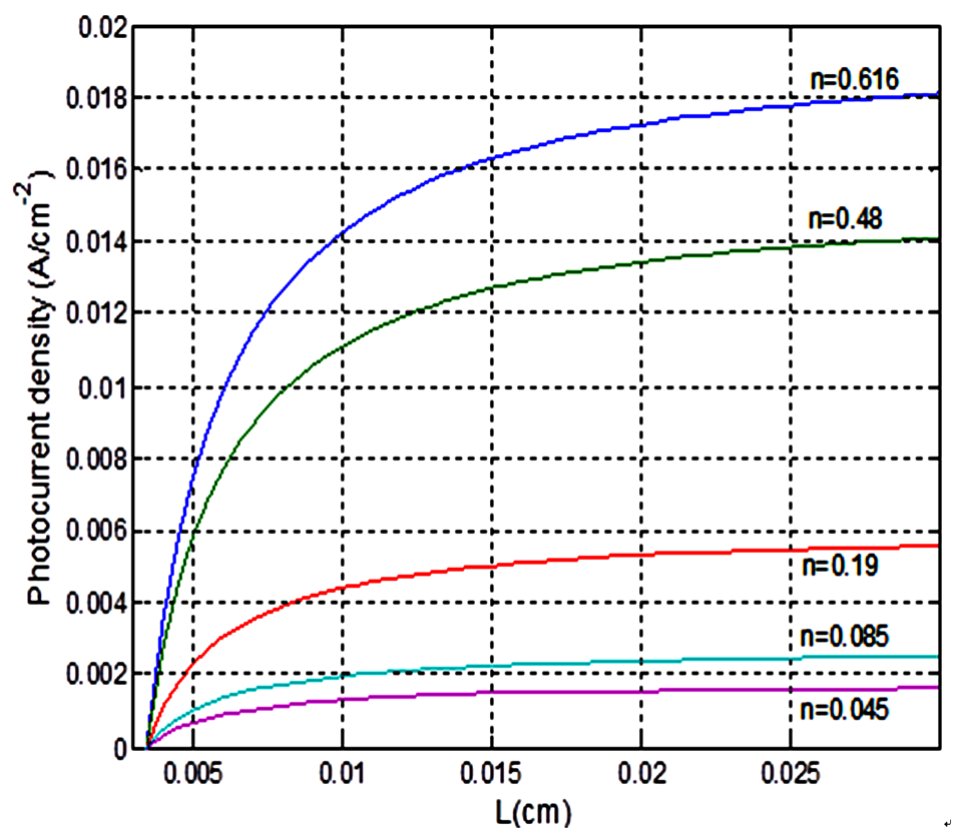

Figure 6. Short-circuit current density according to the diffusion length: $D$ $=26 \mathrm{~cm}^{2} / \mathrm{s}$; illumination on the front face.

\subsubsection{Experimental Device}

Like I. LY et al. [4], the following experimental device shown in Figure 7, has been used to measure the shortcircuit photocurrent and the open circuit photo voltage.

It is constituted by:

- a bifacial solar cell,

- a voltmeter,

- a low resistor $R=1 \Omega$,

- a multispectral lamp $(P=100 \mathrm{~W})$.

When the solar cell is illuminated and the switch $\mathrm{K}$ is open, we measure the open circuit photo voltage $V_{c o}$. On the other hand, if the switch $\mathrm{K}$ is closed, the voltmeter permits to measure the voltage $V_{c c}$ across the load re- 
tance $R$. $i$ e. the voltage across the solar cell. The short-circuit current is given by: $I_{c c}=\frac{V_{c c}}{R}$. For a refersisence distance $d_{0}$ between the lamp and the solar cell, we have $I_{c c}=I_{c c o}$. For any other distance $d$, we have measured the short-circuit current $I_{c c}=I_{c c i}$.

The illumination level being proportional to the photocurrent, it is given by: $n=\frac{I_{c c i}}{I_{c c o}}$.

From these various measurements of illumination level $n$, short-circuit current $I_{c c}$ and open circuit voltage $V_{c o}$, we have determined:

- the diffusion length from the curve $J_{c c}$ according to the diffusion length $L$ (Figure 6);

- the back surface recombination velocity from Equations (15) and (16);

- the intrinsic junction recombination velocity.

\subsubsection{Intrinsic Junction Recombination Velocity}

Knowing the diffusion length value $L$ obtained using the measured short-circuit current, we deduce the back surface recombination velocity using the Equations (15) and (16). These values are then introduced into the Equation (17) leading thus to an expression of the photo voltage witch only is function of the junction recombination velocity. The intrinsic junction recombination velocity can be determined if the measured open circuit photo voltage is known [4]. The results obtained for various illumination levels are consigned in Table 1 for the front surface illumination, and in Table 2 for the back surface illumination.

\subsubsection{Shunt Resistance}

From the values of back surface recombination velocities $S b_{1}$ and $S b_{2}$ obtained in Tables 1 and 2 for various illumination levels, we have determined shunt resistance (Equation (20)) according to the intrinsic junction recombination velocity, for front and back surfaces illumination. We have plotted it in Figures 8 and 9 .

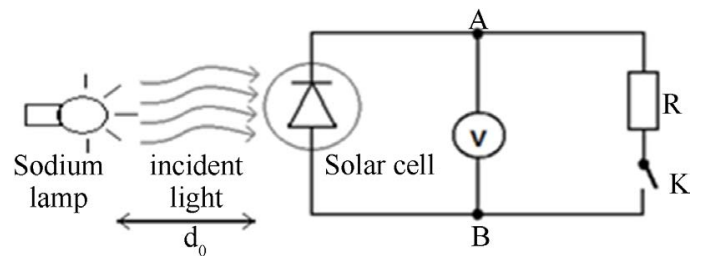

Figure 7. Experimental device.

Table 1. Recombination parameters: front surface illumination.

\begin{tabular}{cccccc}
\hline$n$ & $J_{c c 1}(\mathrm{~mA})$ & $V_{c 01}(\mathrm{mv})$ & $L(\mu \mathrm{m})$ & $S b_{1} 10^{4} \mathrm{~cm} / \mathrm{s}$ & $S j 0110^{5} \mathrm{~cm} / \mathrm{s}$ \\
\hline 0.056 & 1.50 & 445 & 76 & 1.02 & 1,21 \\
0.085 & 2.30 & 408 & 76 & 1.02 & 5,24 \\
0.19 & 5.10 & 490 & 76 & 1.02 & 3.16 \\
0.48 & 13.00 & 510 & 77 & 1.02 & 3.98 \\
0.616 & 16.5 & 525 & 77 & 1.02 & 3.16 \\
\hline
\end{tabular}

Table 2. Recombination parameters: back surface illumination.

\begin{tabular}{cccccc}
\hline$n$ & $J_{c c 2}(\mathrm{~mA})$ & $V_{c o 2}(\mathrm{mv})$ & $L(\mu \mathrm{m})$ & $S b_{2} 10^{5} \mathrm{~cm} / \mathrm{s}$ & $S j o 2 ~ 10^{5} \mathrm{~cm} / \mathrm{s}$ \\
\hline 0.056 & 0.27 & 400 & 76 & 2.03 & 1.23 \\
0.085 & 0.50 & 348 & 76 & 2.03 & 4.82 \\
0.19 & 1.00 & 350 & 76 & 2.03 & 1.00 \\
0.48 & 3.60 & 365 & 77 & 2.02 & 3.16 \\
0.616 & 8.00 & 370 & 77 & 2.02 & 3.16 \\
\hline
\end{tabular}




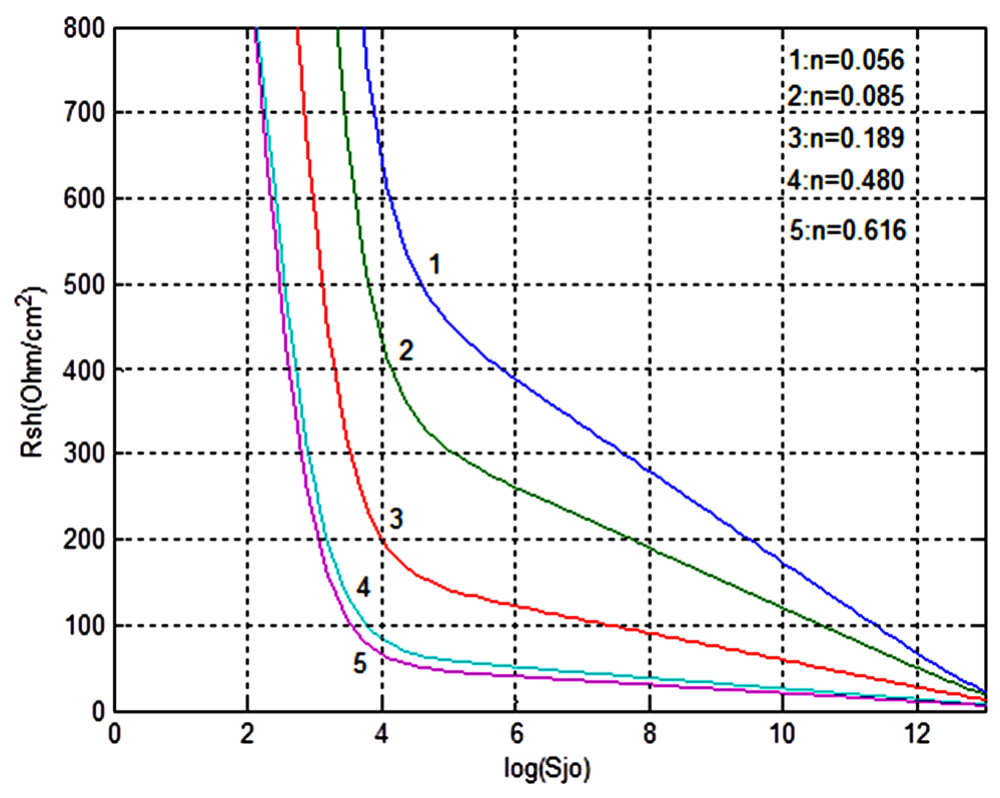

Figure 8. Shunt resistance versus intrinsic junction recombination velocity Sjo: front surface illumination.

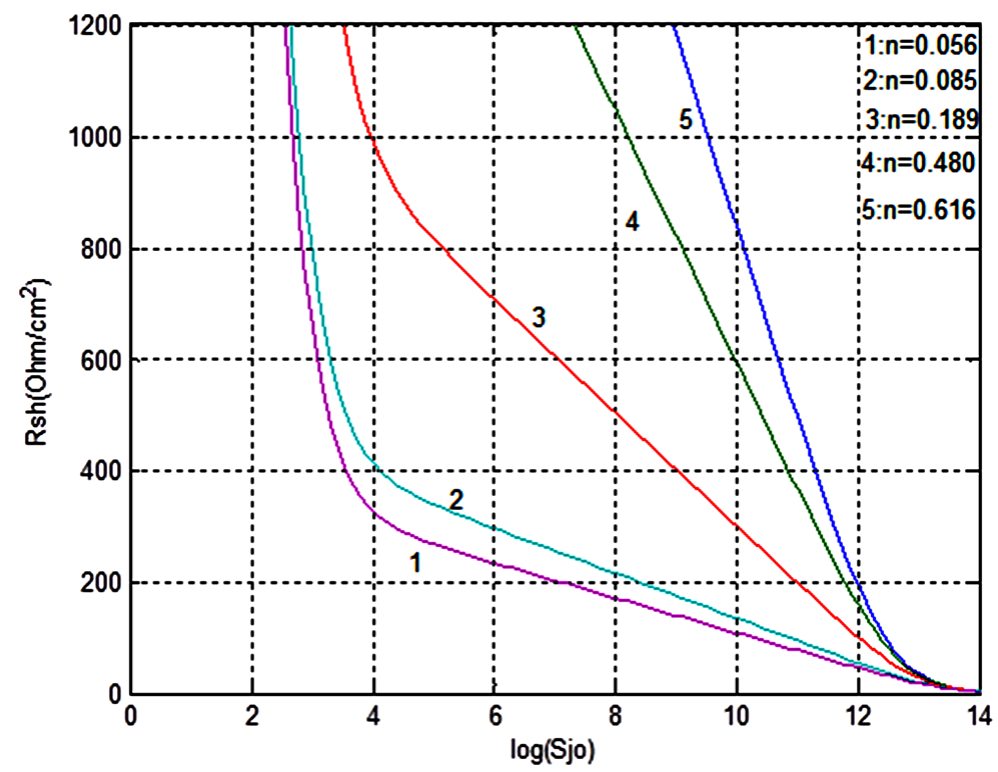

Figure 9. Shunt resistance versus intrinsic junction recombination velocity Sjo: back surface illumination.

We can note that for low values of Sjo, the shunt resistance is high, that is due to the low leak of current for these values of Sjo.

\subsubsection{Series Resistance}

Series resistance is determined when the junction recombination velocity is tending towards infinity. It is given by Equation (21). In Figures 10 and 11, series resistances are represented versus the intrinsic junction recombination velocity respectively, for the front and back surfaces illumination.

One can note that series resistance decreases when the intrinsic junction recombination velocity increases. Sjo being a component of the junction recombination velocity, its increasing would involve an increase current I, 


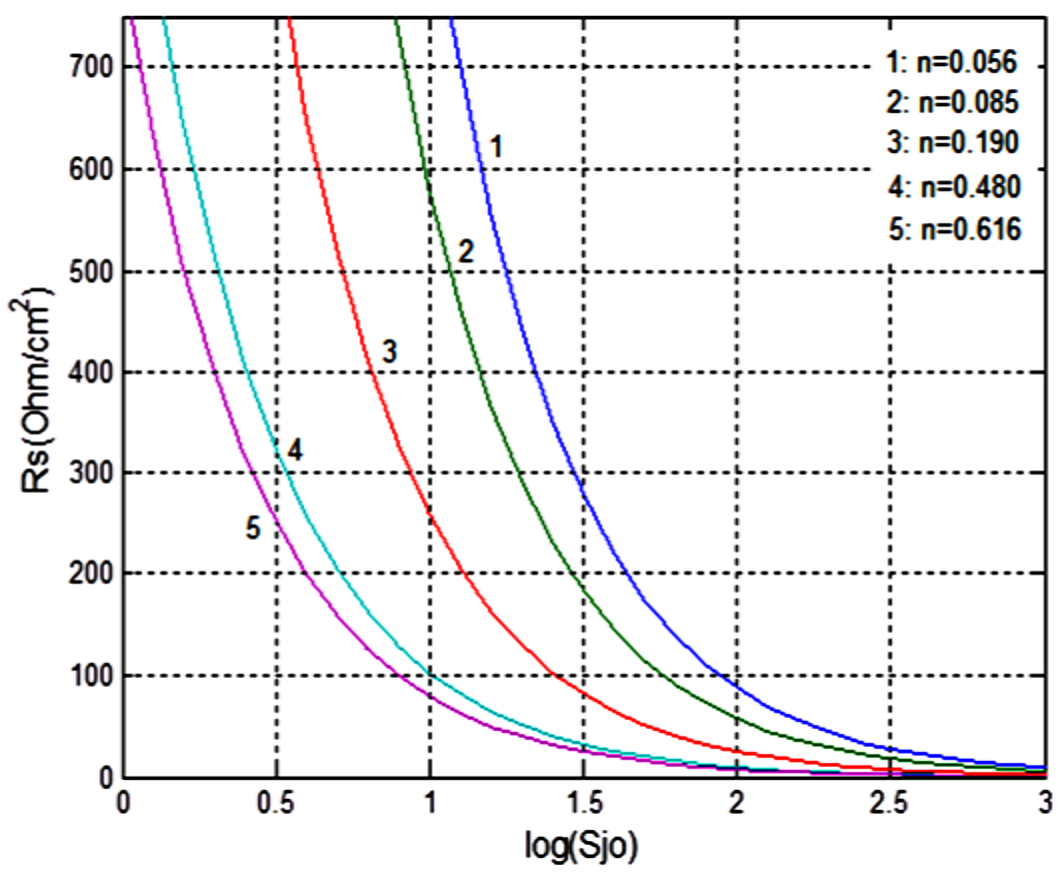

Figure 10. Series resistance versus Sjo: front surface illumination.

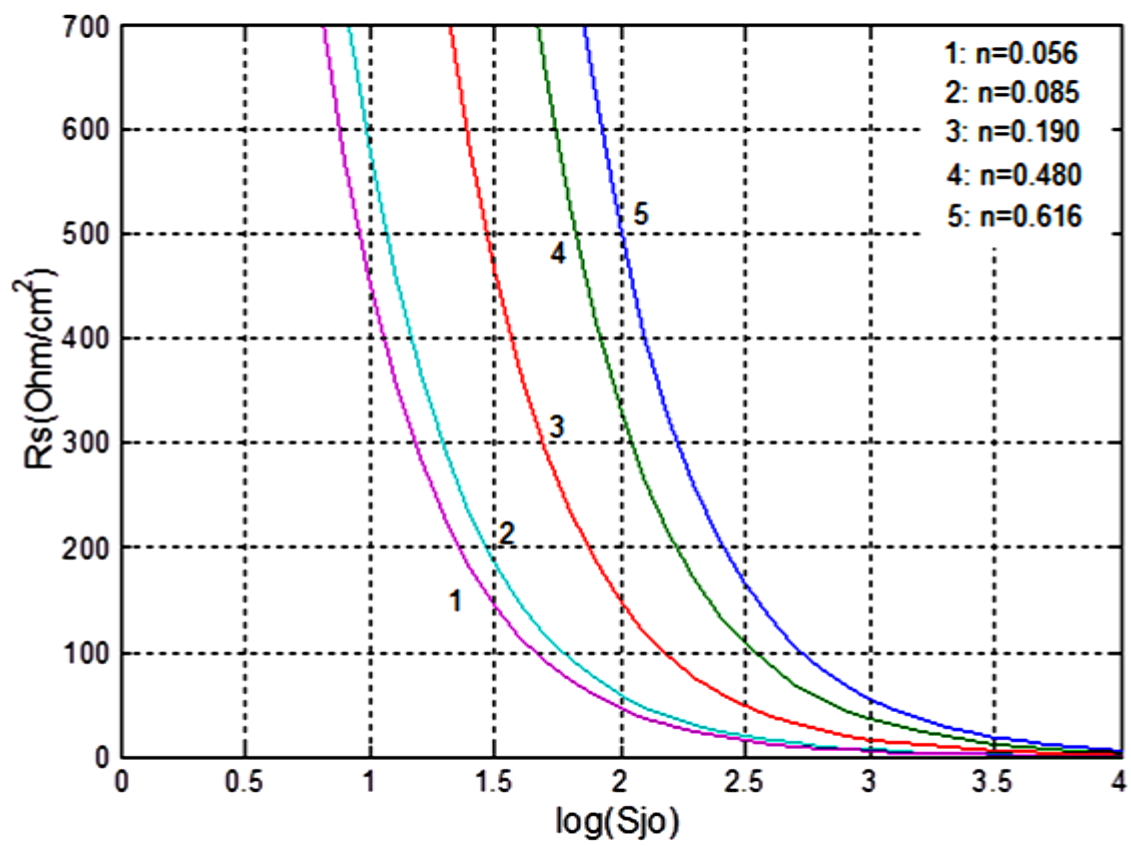

Figure 11. Series resistance versus Sjo: back surface illumination.

and thus a reduction of Rs.

\subsection{Illumination Level Effects on Shunt and Series Resistances}

Knowing the variation of shunt resistance $R_{s h}$ and that of series resistance $R_{S}$ according to the intrinsic junction recombination intrinsic Sjo, we have determined shunt and series resistances, for various illumination levels.

In Figures 12 and 13, we have represented the variations of these resistances according to $n$.

One can note that these resistances decrease with $n$. 


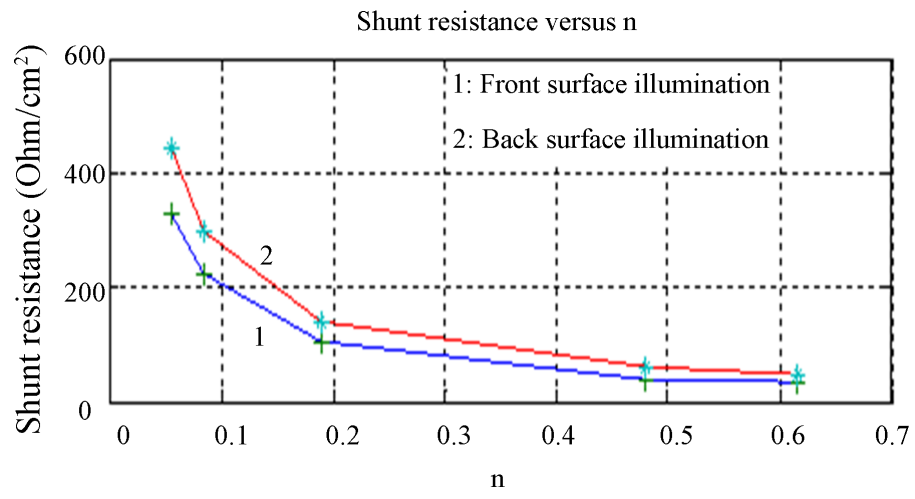

Figure 12. Shunt resistance versus illumination level $n$.

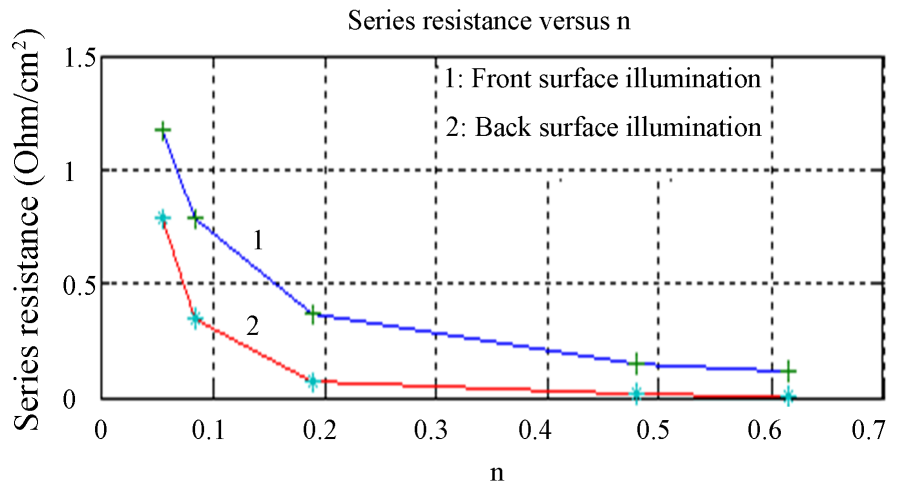

Figure 13. Series resistance versus illumination level $n$.

\section{Conclusion}

This study permits us to present a method of determination of the macroscopic parameters of the solar cell, in particular, shunt and series resistances. This method which has clearly highlighted the illumination level effect on series and shunt resistances of a solar cell can be used for characterization of solar cells.

\section{References}

[1] Gaye, G., Correa, A., Ndiaye, A.L., Nanema, E., Ba, AB.B., Adj M. and Sissoko G. (1996) World Renewable Energy Congress, Part II, 1598-1601.

[2] Sissoko, G., Nanéma, E., Corréa, A., Biteye, P.M., Adj, M. and Ndiaye, A.L. (1998) World Renewable Energy Congress, 1848-1851.

[3] Nzonzolo (2004) Recombination Parameters Determination from the Study of Current-Voltage Characteristic of a Bifacial Solar Cell under Constant Ullimination, Doctorate Third Cycle, Cheikh Anta Diop, University, Dakar.

[4] I. Ly, Lemrabott, O.H., Dieng, B., Gaye, I., Gueye, S., Diouf, M.S. and Sissoko, G. (2012) Technics of Recombination Parameters Determination and the Validity Domain of a Polycrystalline Bifacial Silicon Solar Cell under Constant Multispectral Illumination in Static Mode. www.cder.dz/spip.php?article535

[5] Hamidou, A., Diao, A., Ali Miossi, S.A.D., Thiame, M., Barro, F.I. and Sissoko, G. (2013) Capacitance Determination of a Verticalparallel Junction Solar Cell under Multispectral Illumination in Steady State. International Journal of Inovative Technology and Exploring Engineering (IJTEE), 2, 12-14.

[6] Dia, F.S., Diasse, O., Sam, R.S., Diallo, H.L., Dieng, B., Thiam, N., Mbodji, S. and Sissoko, G. (2012) 1D Modeling Study of Series and Shunt Resistances of Silicon Solar Cell in Steady State Operating Condition and under Polychromatic Illumination. International Journal of Advanced Technology \& Engineering Research (IJATER), 2, 18-23. http://www.ijater.com/Issue.aspx?IssueId=13

[7] Dieng, A., Zerbo, I., Wade, M., Maiga, A.S. and Sissoko, G. (2011) Three-Dimensional Study of Apolycrystalline Silicon Solar Cell: The Influence of the Applied Magnetic Field on the Electrical Parameters. Semiconductor Science and 
technology, 26, 095023.

[8] Thiam, A., Zoungrana, M., Ly Diallo, H., Diao, A., Thiam, N., Gueye, S., Deme, M.M., Sarr, M. and Sissoko, G. (2013) Influence of Incident Illumination Angle on Capacitance of a Silicon Solar Cell under Frequency Modulation. Research Journal of Applied Sciences, Engineering and Technology, 5, 1123-1128. http://www.maxwellsci.com/print/rjaset/

[9] Ould El Moujtaba, M.A., Ndiaye, M., Diao, A., Thiame, M., Barro, I.F. and Sissoko, G. (2012) Theorical Study of Irradiation on Solar Cell under Multispectral Illumination. Research Journal of applied Sciences Engineering and Technology, 4, 5068-5073. http://maxwellsci.com/jp/abstract.php

[10] Diasse, O., Sam, R.S., Ly Diallo, H., Ndiaye, M., Thiam, N., Mbodji, S. and Sissoko, G. (2012) Solar Cell’s Classification by the Determination of the Specific Values of the Back Surface Recombination Velocities in Open Circuit and Short-Circuit Operating Conditions. Journal of Emerging Trends \& Technology in Computer Science (IJETTCS), 1, 55-59. 